\title{
Hybrid of a hybrid: A story in evolution
}

\author{
David M. Overman, MD
}

See related article on pages 350-7.

The submission by Nassar and colleagues ${ }^{1}$ is a thoughtprovoking contribution to the evolving story of hybrid palliation for hypoplastic left heart syndrome (HLHS). The authors propose a strategy of providing pulmonary blood flow by way of a modified Blalock-Taussig shunt (MBTS) at the time of "stage II" palliation (so-called 2-stage Norwood I) rather than the cavopulmonary connection usually incorporated into the "comprehensive stage II" operation. The clinical issue driving this novel strategy is the increasingly well-documented problem of branch pulmonary artery stenosis associated with hybrid palliation of HLHS. ${ }^{2-4}$ The authors' premise that use of an arterial shunt at the time of arch reconstruction may result in improved pulmonary artery architecture is reasonable, and supported, albeit modestly, by a higher lower lobe index score in patients undergoing the MBTS. Nearly all surviving patients who underwent the MBTS have proceeded to a successful cavopulmonary shunt. However, there are several confounding issues that strongly modulate the import of this experience.

First, of course, is the difficulty of claiming "noninferiority" of one strategy over another when the sample size is small, the study design is retrospective, and the therapies being compared are applied noncontemporaneously. However, more important is the complex and heterogeneous nature of patient selection in this series. There are significant differences in age at operation (and presumably, therefore, clinical indications for intervention), a broad and variable array of patient factors, and several different clinical indicators for using one operation over another. These characteristics significantly limit the import of the study's inferences.

Perhaps more troubling is the high rate of clinically detectable postoperative neurologic abnormalities and associated magnetic resonance imaging findings in both

\footnotetext{
From the Division of Cardiac Surgery, The Children's Heart Clinic, Minneapolis, Minn; and Division of Cardiovascular Surgery, Children's Hospitals and Clinics of Minnesota, Minneapolis, Minn.

Disclosures: Author has nothing to disclose with regard to commercial support.

Received for publication May 18, 2015; accepted for publication May 18, 2015.

Address for reprints: David M. Overman, MD, The Children's Heart Clinic, 2530 Chicago Ave South, Suite 500, Minneapolis, MN 55404 (E-mail: doverman@chc-pa.org).

J Thorac Cardiovasc Surg 2015;150:286-7

$0022-5223 / \$ 36.00$

Copyright (C) 2015 by The American Association for Thoracic Surgery

http://dx.doi.org/10.1016/j.jtcvs.2015.05.050
}

treatment groups. The prevalence of this complication, although perhaps attributable to a commendable level of vigilance on the part of the investigators, is problematic as regards one of the central tenets of hybrid strategy: that neurodevelopmental outcome will be improved by delaying larger reconstructive operations

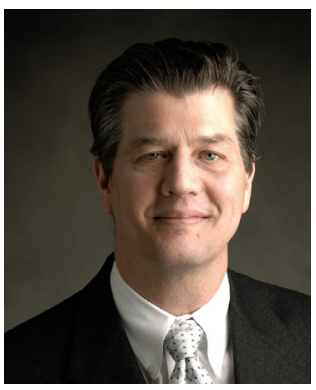
from the neonatal period into infancy. High-risk cohorts such as this one undoubtedly have an increased prevalence of postoperative neurologic complications, and there are data to suggest that such risk factors are, in essence, immutable. ${ }^{5}$ Nevertheless, any strategy associated with such a high rate of detectable brain injury is difficult to endorse.

Finally, a clinical approach that inserts yet another intervention into what is already a complex series of operations, each with its own hazard function, must clearly demonstrate a salutary impact on the risk/benefit calculus before it can be adopted. Exposure to general anesthesia for the operation and associated diagnostic testing, additional exposure to perioperative narcotics and sedatives, hospital-acquired infection risk, nutritional taxation, and many other well-known intervention-related morbidities strongly attest to the advisability of minimizing the number of procedures required to definitively treat a patient.

Standard Norwood palliation is now achieved with mortality rates of $10 \%$ or less at many centers, with a still lower mortality risk at subsequent stages. Hybrid palliation was initially thought to be a therapy that would eventually supplant standard Norwood palliation because of its technical simplicity, its avoidance of general anesthesia and prolonged perioperative recovery periods in the neonatal period, and an intuitive notion that it would be associated with improved neurodevelopmental outcomes. ${ }^{6}$ While we await an answer to this last hypothesis, we can make some observations about the other historical assumptions.

Today, $70 \%$ of institutions in the Society of Thoracic Surgeons Congenital Heart Surgery Database use hybrid strategies in less than $20 \%$ of their patients with HLHS, and $50 \%$ do not use them at all. Only 4 centers use hybrid therapy preferentially over the Norwood. ${ }^{7}$ Clearly, hybrid strategies have failed to convince as an attractive alternative to standard Norwood. The notion of technical simplicity has faded as the timing and nature of atrial septal communication, retrograde coarctation, reverse MBTS, pulmonary arterial reinterventions, and other challenges have occupied 
the attention of investigators. The present report reminds us that hybrid strategies do not relieve a measurable number of patients of the burden of difficult perioperative convalescences and the specter of neurodevelopmental sequelae.

However, it is well established that certain risk factors significantly affect outcomes after standard Norwood palliation. This reality has led to the emergence of a practice pattern wherein hybrid strategies are used for a higher-risk subset of patients, as is the approach used by Nassar and colleagues. ${ }^{1}$ The impact and advisability of this particular approach, although intuitively resonant, are still an open question, mainly because of the analytic challenges of risk-adjusted comparison of therapeutic strategies. Those challenges notwithstanding, there is almost certainly a subset of anatomies in which hybrid strategies are the optimal treatment platform.

The nature and the role of hybrid strategies in the palliation of HLHS and its variants continue to evolve. The arterial shunt at stage II is yet another twist in the evolving story of hybrid therapy for HLHS.

\section{References}

1. Nassar MS, Narayan SA, Nyman A, Salih C, Austin CB, Anderson D, Hussain T Second stage palliation following initial hybrid palliation for hypoplastic left heart syndrome: arterial or venous shunt? J Thorac Cardiovasc Surg. 2015;150:350-7.

2. Dave H, Rosser B, Knirsch W, Hubler M, Pretre R, Kretschmar O. Hybrid approach for hypoplastic left heart syndrome and its variants: the fate of the pulmonary arteries. Eur J Cardiothorac Surg. 2014;1:14-9.

3. Davies RR, Radtke WA, Klenk D, Pizarro C. Bilateral pulmonary artery banding results in an increased need for subsequent pulmonary artery interventions. J Thorac Cardiovasc Surg. 2014;147:706-12.

4. Rahkonen O, Chaturvedi RR, Benson L, Honjo O, Caldarone CA, Lee KJ Pulmonary artery stenosis in hybrid single-ventricle palliation: high incidence of left pulmonary artery intervention. J Thorac Cardiovasc Surg. 2015;149: 1102-10.

5. Davies RR, Radtke W, Bhat MA, Baffa JM, Woodford E, Pizarro C. Hybrid palliation for critical systemic outflow obstruction: neither rapid stage I Norwood nor comprehensive stage II mitigate consequences of early risk factors. J Thorac Cardiovasc Surg. 2015;149:182-93.

6. Galantowicz M, Cheatham JP, Phillips A, Cua CL, Hoffman TM, Hill SL, et al Hybrid approach for hypoplastic left heart syndrome: intermediate results after the learning curve. Ann Thorac Surg. 2008;85:2063-71.

7. Karamlou T, Overman DM, Hill KD, Wallace A, Pasquali SK, Jacobs JP, et al. Stage 1 hybrid palliation for hypoplastic left heart syndrome-assessment of contemporary patterns of use: an analysis of The Society of Thoracic Surgeons Congenital Heart Surgery Database. J Thorac Cardiovasc Surg. 2015;149: 195-202.

Access to The Journal of Thoracic and Cardiovascular Surgery Online is reserved for print subscribers!

Full-text access to The Journal of Thoracic and Cardiovascular Surgery Online is available for all print subscribers. To activate your individual online subscription, please visit The Journal of Thoracic and Cardiovascular Surgery Online, point your browser to http://www.mosby.com/jtcvs, follow the prompts to activate your online access, and follow the instructions. To activate your account, you will need your subscriber account number, which you can find on your mailing label (note: the number of digits in your subscriber account number varies from 6 to 10 ). See the example below in which the subscriber account number has been circled:

\section{Sample mailing label}

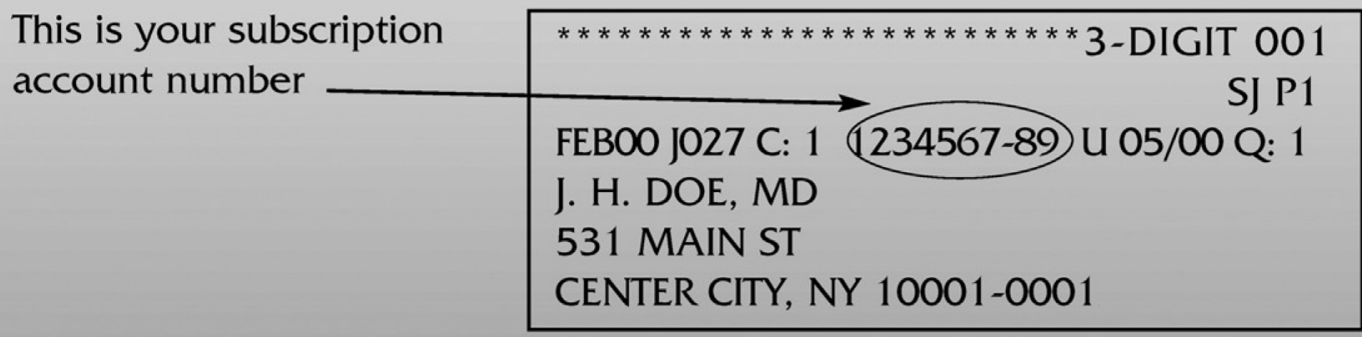

Personal subscriptions to The Journal of Thoracic and Cardiovascular Surgery Online are for individual use only and may not be transferred. Use of The Journal of Thoracic and Cardiovascular Surgery Online is subject to agreement to the terms and conditions as indicated online. 